\title{
Prostate Cancer Pathologic Distant Metastasis TNM Finding v7
}

National Cancer Institute

\section{Source}

National Cancer Institute. Prostate Cancer Pathologic Distant Metastasis TNM Finding

v7. NCI Thesaurus. Code C89205.

A pathologic finding about one or more characteristics of prostate cancer, following the rules of the TNM AJCC V7 classification system as they pertain to distant metastases.

There is no pathologic M0 for prostate cancer. When more than one site of metastasis is present, the most advanced category is used. pM1c is most advanced. (from AJCC 7th Ed.) 